\title{
O "RETRATO" DO HOSPITAL DA MISERICÓRDIA DE VILA VIÇOSA (PORTUGAL) EM 1870
}

\author{
Maria Marta Lobo de Araújo \\ Universidade do Minho-Portugal \\ e-mail: martalobo@ics.uminho.pt \\ ORCID iD: https://orcid.org/0000-0002-6199-8033
}

Recibido: 21 octubre 2017; Aprobado: 22 diciembre 2018.

Cómo citar este artículo/Citation: Araújo, María Marta Lobo de (2019), "O 'retrato' do hospital da Misericórdia de Vila Viçosa (Portugal) em 1870" Asclepio 71(1): p251. doi: https://doi.org/10.3989/asclepio.2019.03

RESUMO: O nosso estudo analisa o hospital da Misericórdia de Vila Viçosa em 1870 com base na descrição elaborada pelo administrador do concelho nessa data. Os elementos fornecidos procuram conhecer a instituição a que está ligado -a Misericórdia-, e contribuir para uma melhor administração.

Com base nesta fonte é possível conhecer o hospital, bem como a política seguida pela confraria no tocante à saúde. O seu estudo dá a conhecer o funcionamento da instituição, desde os seus espaços aos doentes, apresentando um hospital Municipal de traça quinhentista, embora adaptado às necessidades do século XIX.

Integra ainda as sugestões do administrador do concelho, embora estas não sejam implementadas devido à escassez de receitas com que o hospital se debatia, as quais eram as responsáveis pelo estado de degradação em que alguns dos seus espaços se encontravam, mas sobretudo pelo corte no internamento de doentes e da assistência aos que se curavam em suas casas.

PALAVRAS-CHAVE: complexo hospitalar, doentes, Misericórdia, Vila Viçosa.

\section{THE "PORTRAIT" OF THE HOSPITAL OF THE MISERICÓRDIA DE VILA VIÇOSA (PORTUGAL) IN 1870}

ABSTRACT: Our study analyzes the hospital of the Misericórdia of Vila Viçosa in the 1870, based on the description made by the county administrator in that date. The elements given provided seek to know the institution in which is connected - the Misericórdia -, and to contribute to better administration.

Based on this source is possible to know the hospital, as well as the politic pursued by the brotherhood in regards to the health. Its study makes known the functioning of the institution, from its spaces to the sick people, presenting a Municipal hospital of fifths hundred traces, although tailored to the needs of the XIX century.

It also integrates the suggestions of the municipal administrator, although these are not implemented due to the lack of revenue that the hospital was debating, which were responsible for the state of degradation in which some of its spaces were located, but especially for the cut in hospitalization and the care of those who were cured in their homes.

KEY WORDS: hospital complex, sick people, Misericórdia, Vila Viçosa. 


\section{INTRODUÇÃO}

O documento enviado pelo administrador do concelho, José António Dias Azevedo, em 24 de Novembro de 1870, ao governador civil de Évora (capital de Distrito, Alto Alentejo) descreve pormenorizadamente o "Estabelecimento de Beneficencia do Concelho" de Vila Viçosa (Alentejo, sul de Portugal) ${ }^{1}$ dando a conhecer a única instituição de apoio à saúde do Município. Nele, destacou as suas funcionalidades, forneceu informações sobre a sua história e a da Misericórdia ${ }^{2}$ a que pertencia, e mencionou as receitas, as despesas e as suas dívidas ativas e passivas. Trata-se de uma fonte importante, que procurou responder a uma solicitação do representante do Governo Central, com sede em Évora.

O administrador respondeu a um questionário emanado do Governo Civil, procurando conhecer o local em que a Misericórdia e o hospital se encontravam, a época e as circunstâncias da sua fundação, a legislação que os regia, os regulamentos internos e assalariados que possuíam, vencimentos que usufruíam, receita e despesa, número anual de doentes tratados e encargos pios existentes. Pretendia-se um retrato tanto quanto possível exato da Misericórdia, tendo o hospital sobressaído em função do lugar central que nela ocupava. Nesse momento, como já vinha acontecendo sobretudo desde meados do século, a ação assistencial da Santa Casa centrava-se quase exclusivamente no hospital.

Esta ação vinha na sequência da intromissão cada vez maior do Estado nestas instituições, conhecida principalmente com o Liberalismo, mas já anteriormente em prática (Lopes, 2008, pp. 131-176). Porém, com o regime Liberal, a intervenção do Estado acentua-se, tentando controlar estas instituições. Procurava rastrear a instituição, uma vez que se encontrava com dívidas incontroláveis e numa situação de caos financeiro. A data de 1870 assume particular relevância por se estar num momento de acentuada crise institucional, mas também de grande rotatividade partidária e de instabilidade política em termos nacionais.

Durante o século XIX, a Santa Casa de Vila Viçosa conheceu um dos piores períodos da sua existência, vendo-se obrigada a tomar medidas muito restritivas no campo hospitalar para se manter aberta, todavia conheceu vários momentos em que esteve de encerrar as suas portas. A crise vivida em Portugal entre 1868 e 1870 teve reflexos profundos na Santa Casa e esteve na base da implementação de novas medidas conducentes à diminuição de despesas.

No século XIX, Vila Viçosa já não tinha o brilho e grandeza dos séculos anteriores, quando os duques de Bragança, futuros reis de Portugal, lá viviam, mas contava com um hospital de consideráveis dimensões, fruto do investimento que os próprios duques e reis fizeram nele.

O estudo do hospital de Vila Viçosa no período assinalado reveste-se de importância pela escassez de trabalhos para o setor hospitalar em Portugal para a mesma altura, o que já não acontece na Europa, mas principalmente por se saber muito pouco ou quase nada sobre a intervenção do Estado, através dos seus representantes locais, nestas instituições. Se para os séculos anteriores, os hospitais portugueses se encontram razoavelmente trabalhados e abunda a bibliografia, para o período em questão, os trabalhos são muito menos, pese embora o surgimento de algumas teses de doutoramento sobre a saúde na Época Contemporânea. Todavia, sobre o interior das instituições e o seu funcionamento quotidiano, a escassez é a tónica dominante.

\section{O PERCURSO DO HOSPITAL E OS ESTUDOS SOBRE A ASSISTÊNCIA AOS DOENTES}

A descrição que o administrador concelhio fez do hospital em 1870 é muito semelhante ao que ainda hoje se pode observar, porque o edifício permanece sem grandes alterações. O hospital mantém praticamente a mesma estrutura conhecida para os séculos XVII e XVIII. Ao longo dos tempos, a instituição foi sendo adaptada às necessidades sentidas, todavia, é ainda hoje possível identificar vários dos espaços mencionados pelo administrador concelhio.

O hospital do Espírito Santo, instituição que em 1510 passou para a administração da Misericórdia, era medieval (Correia, 1943, p. 180), pertencente à Casa de Bragança ${ }^{3}$. Foi integrado na Misericórdia da vila em 1510, por ordem do duque D. Jaime. Cresceu com a Santa Casa ao longo dos séculos XVI e XVII, sob a proteção da casa ducal, mas tinha já um historial. Durante a sua existência foi sujeito a várias remodelações, no sentido de aumentar o espaço em que se encontrava em Quinhentos e proporcionar instalações mais cómodas e adaptadas às exigências com que se via confrontado. 
O hospital cresceu para Sul e Oriente e passou a ter mais duas enfermarias: uma para homens e outra para mulheres, que funcionavam apenas na Primavera e no Outono, períodos considerados mais adequados ao tratamento a que os doentes eram sujeitos para combater "os males" de que eram portadores. Contava com 6 enfermarias: a de São José, destinada ao acolhimento de homens, a de Nossa Senhora da Visitação, onde se recolhiam as mulheres, a que recebia pessoas consideradas de "qualidade" e as duas dos doentes dos "males" venéreos. Mais tarde, foi construída ainda uma outra para convalescentes. Sublinhe-se que estas duas enfermarias, designadas nas fontes como "hospital dos males" eram as únicas da região em que se procedia ao tratamento desta doença. Como é sabido, os portadores destes "males" eram tratados em locais distintos dos restantes internados devido ao forte contágio. Estas enfermarias pertenciam também à Casa de Bragança e foram por ela integradas no hospital da Santa Casa.

A instituição foi aumentando e alargando as suas estruturas à custa dos prédios vizinhos que a Misericórdia foi comprando nas ruas de Três e das Vaqueiras. Na primeira metade do século XVI, Vila Viçosa modernizou-se e assistiu a uma renovação urbanística, a qual esteve muito associada ao crescimento e afirmação da Casa brigantina (Teixeira, 2007, p. 20).

Com um forte amparo e investimento da Casa de Bragança, a Misericórdia e o hospital prosperaram, sobretudo nos séculos XVI e XVII (Cunha, 2000, p. $374)$, mas receberam também outros legados provenientes essencialmente de pessoas da terra, gente rica que, à semelhança do que era vulgar, entendia poder alcançar mais facilmente a salvação através da caridade. O período de maior prosperidade da Misericórdia e do hospital verificou-se entre meados do século XVI e 1640, data em que os duques, por residirem na vila, os beneficiaram não apenas com a sua presença, mas sobretudo com doações e com a "gestão" que faziam da Santa Casa desde o seu Paço. A confraria era entendida como parte integrante da Casa ducal e, apesar de ter órgãos próprios eleitos anualmente, era "governada" em conformidade. A partir de 1640 com a partida dos duques para Lisboa onde se tornaram reis, Vila Viçosa conheceu num período mais apagado, que se prolongou por todo o século XVIII. A vila ficou "órfã" dos duques, mas também da nobreza que com eles abalou para a capital. A Misericórdia ressentiu-se, embora continuasse a desempenhar um papel de significativa importância no combate à pobreza local. A instituição de tratamento à saúde da Santa Casa foi confrontado com um volume maior de doentes, no contexto da Guerra da Restauração, principalmente a partir de 1661, data em que a citada guerra atingiu níveis de maior beligerância e a Coroa assinou um tratado com a Misericórdia para tratar as tropas no seu hospital. Devido à sua localização geográfica e ao simbolismo da vila, o hospital conheceu como nunca uma avalanche de militares, obrigando os naturais a serem tratados em suas casas. Esta situação fez com que o hospital se mantivesse sempre superlotado, embora a pressão que sobre ele foi exercida diminuísse após 1668, término da guerra. Nos finais do século XVIII, uma vez mais os militares regressaram em força ao hospital, devido às condições bélicas existentes na Europa e em Portugal, o que teve como consequência as enormes despesas na instituição por eles provocadas e a falta de condições físicas para atender os locais.

No século XIX, as invasões francesas, as guerras civis e as crises económicas e financeiras deixaram marcas profundas na Santa Casa e no seu hospital, pois exigiram dele um enorme esforço para tratar os militares que encheram as suas enfermarias. A instituição teve de reforçar o seu plantel de profissionais de saúde, de outros assalariados e de aumentar a burocracia nos intensos contactos com o Exército. Foi ainda neste período que a presença de "alienados" acrescentou mais dificuldades à Santa Casa. Instituições de assistência com uma enorme função social, os hospitais portugueses estavam em grande número associados às Misericórdias e cumpriam a relevante obra de curar o corpo e de assistir a alma. Todavia, não estavam preparados para lidar com os doentes mentais. Se a historiografia portuguesa tem trabalhado e dado a conhecer estas instituições na Idade Moderna, o período que se lhe segue carece de maior investimento, bem como os hospitais psiquiátricos surgidos em oitocentos.

\section{O HOSPITAL NA PENA DO ADMINISTRADOR DO CONCELHO}

O edifício hospitalar foi considerado em 1870 pelo administrador do concelho em "soffrivel estado", necessitando, por conseguinte, de reformas importantes, sentidas também pelos mesários ${ }^{4}$ mas que 0 cofre da Santa Casa não permitia, por se encontrar sem recursos. A confraria encontrava-se numa crise aguda, que atacava todo o país, agravando a já difícil 
situação em que estava a instituição alentejana (Araújo, 2010, pp. 63, 112).

Nesse momento, mais do que dar, a Misericórdia pedia para poder manter-se aberta e ajudar os mais pobres. Recorreu a um empréstimo bancário de um conto de réis ao Banco União do Porto, em 1865, solicitou aos rendeiros que lhe pagassem as dívidas em atraso, pediu aos fornecedores que esperassem pelos pagamentos, porque não lhes podia pagar, e solicitou alguns bens dos conventos da vila extintos ao arcebispo de Évora para substituir os seus que não apresentavam condições de funcionalidade. Enfim, conhecia uma situação muito grave que se prolongou desde os anos 40 do século, sendo apenas matizada por alguns períodos de pouco alívio.

Nas considerações efetuadas sobre a história da Misericórdia e do hospital, o administrador concelhio proferiu afirmações incorrectas, por falta de dados fiáveis, e hesitou quanto à data da fundação do hospital. Referiu "supor-se está a Casa na posse d'elle, desde a fundação do Hospital"5, o que não correspondia à verdade. A instituição tinha raízes medievais e sido propriedade da Casa de Bragança. Posteriormente, foi incorporada na Misericórdia, como dissemos, a mando do duque D. Jaime (Araújo, 2000, pp. 169-171).

As informações veiculadas foram colhidas junto de alguns mesários antigos, uma vez que não existiam documentos que atestassem a sua fundação. Já quanto à sua passagem para a Misericórdia, a carta de D. Jaime, existente no arquivo da Santa Casa, onde se faz a sua incorporação, prova a data da sua integração na confraria, mas o administrador não o consultou.

O hospital era, pelo menos desde o século $\mathrm{XVI}$, constituído por dois pisos, com funcionalidades bem delimitadas: o rés-do-chão e o primeiro andar. Em 1870 , no rés-do-chão encontrava-se situada a maioria das estruturas de apoio ao seu funcionamento: arrecadações com lenha, palha, carvão, madeiras, roupa dos doentes, capela onde se depositavam os cadáveres, casa dos viajantes, açougue e botica. Na parte Norte estava localizada a igreja, ereta em 1565, e algumas estruturas de apoio ao setor religioso: sacristia da confraria das Almas, casa das bandeiras, etc. No piso superior, ficavam as enfermarias, as dependências reservadas aos enfermeiros, ao internamento de velhos, a cozinha e a secção administrativa. Setores bem delimitados que demarcavam distintas funcionalidades.
Situado na rua do Espírito Santo, o hospital estendia-se em 1870 para a rua de Três, onde tinha e tem $a^{6}$ sua entrada principal e para a rua das Vaqueiras, embora o administrador do concelho não tenha tido o cuidado de mencionar a parte Nascente do edifício, destacando somente os quintais nela situados. Após a porta principal que dava acesso à rua, seguia-se um pequeno corredor que levava ao pátio, onde se localizava à direita a botica ${ }^{7}$ e à esquerda os aposentos do campainheiro ${ }^{8}$. A botica tinha acesso fácil para a rua de Três, possibilitando às pessoas exteriores à instituição a entrada e a aquisição de medicamentos sem terem de entrar no pátio do hospital. Para além de espaço de venda, a primeira sala, possuía uma segunda onde se manipulavam os compostos e faziam os medicamentos. Esta localização encontrava-se em muitos hospitais e visava a não intromissão de estranhos no espaço hospitalar. Ao fundo do corredor existia um "arco com cancellos" impedindo o acesso ao pátio, o qual se encontrava "ornado d'arvoredo". No pátio estava localizado um poço de onde se retirava água para o estabelecimento.

No rés-do-chão havia quatro corredores, ladeando o pátio quadrangular. Este pátio facilitava a comunicação interna, mantendo como refere Vera MagaIhães "a morfologia das galerias conventuais" (MagaIhães, 2011, p. 146). Na Idade Moderna, a arquitetura hospitalar reflete, em muitos casos, o traçado dos edifícios religiosos que se estruturavam a partir dos claustros. Também no hospital de Vila Viçosa, o pátio assume um carácter estruturante no edifício, sendo a partir dele que se distribuem as restantes partes do complexo.

Os corredores estavam delimitados através de "portados", restringindo o acesso aos vários compartimentos que nele se encontravam e servindo de mecanismo de segurança (Esteves, 2015, p. 3). Assim, o do lado Sul, dava acesso a um pequeno cemitério interior, o "antigo cemitério da Casa", o qual se encontrava à data "adornado com arvoredo e flores" . Para além deste cemitério, existia outro na praça, situado defronte da igreja da confraria, mantendo-se em atividade até 1839 , altura em que foi criado o cemitério de São José, sendo desativados os dois da Misericórdia.

Após a construção do cemitério de São José, os enterros passaram a ser realizados num local mais longínquo do complexo da Santa Casa, obrigando o desfile a passar pela praça central da vila. Essa situação levou os confrades a maior esmero, porque 
estavam sujeitos a mais olhares e a julgamentos públicos $^{10}$.

O aparecimento de cemitérios públicos ficou a dever-se à lei de 21 de Setembro de 1835, que ordenava a sua construção. Os princípios higienistas conheceram na Europa uma grande difusão ainda no século XVIII. Também em Portugal se sentiram os seus ecos, principalmente através da voz de alguns médicos e filósofos. Ribeiro Sanches deu o maior contributo com a sua obra "Tratado da Conservação da saúde dos Povos", onde defendeu um volume importante de reformas para a saúde pública (Abreu, 2013, pp. 73-75).

Porém, se em alguns dos hospitais portugueses das grandes cidades se começa a dar mais atenção a estes aspetos, na maioria deles, sobretudo nos de menor dimensão, o panorama era desolador. Os mais pequenos e mais pobres arcavam com muitos problemas em termos de falta de roupa de cama, de profissionais de saúde atualizados e lutavam com uma grande carência de verbas para novos programas de tratamento e cura.

Impunha-se tratar da limpeza e desinfeção dos edifícios, mas também implementar novas medidas de higiene corporal. Estratégias para prevenção da doença não existiam. Sempre que ocorriam epidemias, o problema agravava-se e as autoridades públicas e sanitárias agiam mais energicamente para as combater, mas sem uma atitude preventiva e consequente. Recordo a cólera, o tifo, a febre-amarela e a tuberculose. As águas, a alimentação, as casas, os açougues, os tanques, as ruas ficavam na mira das autoridades, chamando a atenção para os graves problemas de saúde pública existentes e a necessidade de os enfrentar e controlar. Foi também nesta centúria que a imprensa veiculou de forma mais sistemática estes assuntos e a ciência avançou em direção à "laboratorização da higiene" (Pereira; Pita, 2011, pp. 92-95).

Os princípios higienistas e a prática seguida em outros países ditaram o fim dos enterros dos cadáveres dentro das igrejas e a construção de locais preparados para esta finalidade. A lei determinava a construção de cemitérios públicos em todas as povoações, bem como o modo de proceder respeitante às sepulturas. Os cemitérios deveriam ser construídos fora das povoações, cercados por muros e estarem situados em local salubre. As sepulturas deveriam ser individuais e manter um certo afastamento entre elas, cabendo a gestão destes locais às autoridades políticas locais (Catroga, 1993, p. 596).

A questão dos cemitérios ganhou realce no século XIX e esteve associada a uma maior preocupação com a saúde pública. Logo no início do século, se manifestou descontentamento e apreensão com a forma como eram feitos os enterros e com os locais de enterramento (Oliveira, 1992, p. 19).

O movimento de construção de cemitérios públicos na vila foi quase imediato ao aparecimento da lei. Ao mesmo tempo que foram construídos, eram desativados os antigos locais de enterramento. Para erguer o cemitério, a Junta da Paróquia de São Bartolomeu de Vila Viçosa solicitou ajuda à Misericórdia, sabendo que ela precisava de o utilizar para sepultar os pobres que sucumbiam no hospital, assim como outros que auxiliava no momento da morte. A resposta enviada foi positiva, embora desconheçamos os termos em que a colaboração foi efetuada.

No hospital, um outro corredor dava acesso a um compartimento onde se guardava a lenha usada na cozinha e nos fogareiros das enfermarias que se acendiam no Inverno. Guardava ainda objetos da botica. Outro "portelo" estabelecia ligação com um corredor, onde se encontravam as arrecadações e um pequeno quintal, "plantado de arvores, e n'elle estão situadas as latrinas"11 e com o compartimento que albergava os pobres portadores de carta de guia, ou seja, os viajantes. O hospital continuava no século XIX a receber mendigos com carta de guia, num espaço separado dos restantes doentes (Sá, 1996, p. 95).

Junto ao corredor Sul encontrava-se uma escada, ligando-o ao primeiro piso. Trata-se de uma escada de "cantaria". Este acesso, ainda que não seja imponente, separa dois importantes espaços: o rés-do-chão do primeiro andar, lugar onde se encontravam as enfermarias.

A varanda, toda envidraçada, assumia um papel principal, onde se encontravam as enfermarias, a cozinha e outras dependências. Porém, depois de se entrar no pátio, nem todos acediam ao piso superior, devido às cancelas existentes, que impediam a circulação de intrusos ao espaço de internamento e que os doentes deixassem o internamento sem autorização.

A enfermaria das mulheres estava localizada à esquerda da parte Sul e tinha teto e paredes estucadas. Acomodava 12 camas, onde se deitavam doentes e 
entrevadas e possuía um altar ${ }^{12}$, mandado colocar em 1830, depois das obras realizadas em 1825 (Araújo, 2010, p. 145). Neste espaço de internamento encontrava-se um guarda-roupa com gavetões para receber os pertences das doentes. A luz e a circulação do ar entravam por uma janela grande, situada à direita da enfermaria, bem como de duas aberturas mais pequenas.

Proporcionar mais comodidade aos doentes e meIhores condições de salubridade foram aspetos reclamados quer pelos higienistas, quer pelos profissionais de saúde. O arejamento dos espaços hospitalares tornou-se numa questão central na segunda metade do século XIX. A higienização e a renovação do ar eram considerados fatores de peso na alteração do estado de saúde dos doentes (Pacheco, 2008, p. 140). Estas preocupações tinham reflexo nas obras efetuadas, causando, por vezes, discórdia entre os homens do poder. Mais sensíveis uns do que outros a estas questões, travavam-se de razões, procurando equilibrar despesas com o melhoramento dos espaços, dotando-os de estruturas promotoras de bem-estar para os doentes.

No mesmo corredor existiam as habitações dos enfermeiros e um quarto para partos. Este compartimento foi criado em 1853 e nele existia apenas uma cama de ferro e uma mesa de apoio ao serviço das parturientes ${ }^{13}$. A existência desta sala materializa as preocupações com a maternidade, porém a maioria dos partos era realizada em casa por mulheres habilidosas, mas que não dispunham de nenhuma formação adequada. Enquanto nas grandes cidades alguns partos já ocorriam nos hospitais, no resto do país nascia-se em casa. O parto constituía um momento de grande perigo e risco quer para as mulheres, quer para os bebés, tornando a taxa de mortalidade infantil muito elevada.

Um "portado" do outro lado da varanda permitia aceder a um quarto reservado a doentes particulares, ou seja, a quem pagava o seu internamento, embora o regulamento em vigor não mencionasse o montante a despender ${ }^{14}$. O regulamento do hospital de 1852 estabelecia o encerramento das portas que acediam à varanda de dia e de noite, exceto nas horas das visitas $^{15}$.

O mesmo corredor, dava acesso à cozinha

"[...] grande e quadrada [...] com armários [...] na parede da esquerda ha duas pequenas dispensas [...] na parede de frente ha no meio uma bella pia de marmore, e por cima d'ella uma janela com vidros que dá luz [...]"16.

À esquerda abria-se uma porta que possibilitava à cozinheira a entrada nos aposentos e à direita uma outra que permitia o acesso a uma escada de cantaria que conduzia a um quintal. Aí encontrava-se o galinheiro e alguma lenha, ou seja, a cozinheira acedia diretamente a alguns produtos da horta, bem como à lenha e às aves do capoeiro sem ter que recorrer a outros espaços. A escada permitia ainda ligação ao exterior do edifício sem passar pelas enfermarias e pelo pátio central do hospital, uma vez que dava acesso à rua das Vaqueiras. Era ainda por esta escada que saía a comida para entregar aos presos e a outros pobres, principalmente até meados do século XIX.

Na parte Norte da varanda existia a "casa dos Invalidos", onde se acomodavam seis entrevados, num compartimento que lhes era destinado, o que já não acontecia com as mulheres.

O fiel tinha o seu lugar de trabalho ao fundo do corredor. O seu "escritório" estabelecia ligação com outro pequeno quarto onde se arrecadavam os géneros alimentares, adquiridos para a confeção das refeições dos doentes internados e dos pobres que a Casa alimentava ${ }^{17}$, controlando todos os víveres da instituição. Este assalariado assumia grandes responsabilidades, porquanto Ihe competia efetuar as compras para o hospital, zelar pelo seu bom funcionamento e proceder à escrita da instituição. A centralidade e a importância das suas funções encontram eco na localização do seu posto de trabalho, situado bem no centro do complexo hospitalar.

À esquerda desse corredor, através de uma porta acedia-se à igreja "por onde se vai buscar o sagrado viático para os Enfermos das Enfermarias"18. Esta ligação existia em muitas igrejas de Misericórdias que tinham hospitais acoplados e possibilitava ao capelão de dia e de noite aceder aos locais de internamento em tempo útil, sem sair do edifício.

De fronte, um arco estabelecia ligação com a "casa das bandeiras" e esta com a "casa dos balandraus"19. Por sua vez, desse compartimento acedia-se a uma varanda que "fica nas costas da Enfermaria da Cyrurgia"20.

O complexo hospitalar estabelecia ligação com as dependências da igreja e estas com uma área de cariz administrativa, localizada a Norte, virada para a praça central da vila. 
Da "casa das bandeiras" passava-se ao púlpito da igreja e a uma sala "vaga onde esperam os requerentes com pendencias da Administração da Casa: ha n'esta salla uma escada que conduz á porta denominada do taboleiro que dá sahida para a Praça" ${ }^{21}$, mas afastada do espaço de internamento, de maneira a não perturbar o ambiente de silêncio e de sossego dos internados. Por aqui, passando uma outra porta, os assalariados, inválidos e doentes reuniam-se para assistir aos ofícios divinos. Essa dependência configurava um local de separação entre os que se encontravam dentro de portas e a restante população da vila que assistia ao culto.

A fachada do edifício, voltada para a praça, era composta por várias janelas, tal como o consistório ${ }^{22}$. A sala consistorial possuía janelas quer para a praça, quer para a rua do Espírito Santo e estabelecia passagem para a sala do arquivo, situado perto de uma arrecadação onde se guardavam o cofre e as roupas do hospital ${ }^{23}$.

"Os baixos" e a sala do consistório estavam arrendados a lojistas, pois reuniam condições para estas funções: possuíam porta para a praça e a sala que se encontrava vaga servia de sacristia à confraria das Almas. Alugar alguns dos seus espaços era uma maneira de os rentabilizar em termos financeiros.

Depois de ter analisado a parte Sul, Oeste e Norte do hospital, o administrador destacou o lado Poente, onde se encontrava a enfermaria de cirurgia para homens, a qual "he estucada no tecto e paredes e acomoda sete camas; tem [...] um grande guarda roupas com porta e gavetões"24. No mesmo corredor encontrava-se também a "Enfermaria de Medicina" para homens com dezoito camas, tendo no "topo [de] um bello Altar de marmore igual a da Enfermaria das mulheres ${ }^{25 \prime \prime}$.

O peso do sexo masculino no internamento hospitalar é notório no número de camas que lhe estava destinado, bem como na divisão entre enfermaria de cirurgia e de medicina. À semelhança de outros hospitais alentejanos (Araújo, 2003, pp. 341-409), o de Vila Viçosa internava um número muito expressivo de homens, em quantidade superior ao de mulheres, o que se verificava desde a Idade Moderna (Araújo, 2000, pp. 184-186) e configura característica de alguns hospitais portugueses já estudados (Abreu, 1999, pp. 404-406). Situado numa região de forte migração, sobretudo masculina, proveniente do Norte e Centro do país, constituída por gente que ia tra- balhar nas diferentes tarefas do campo, quando se encontrava doente, era no hospital que procurava apoio (Picão, 1983, p. 240).

O hospital possuía no momento em que foi avaliado pelo funcionário régio mais de 43 camas. Só as existentes nas enfermarias dos homens, das mulheres e do quarto dos inválidos totalizavam o número mencionado. Porém, não foram referidas as do quarto particular, nem as que recebiam "alguns inválidos sem animo". Sabe-se que quando as enfermarias estavam cheias, a capacidade de receber doentes aumentava, tendo-se recorrido a "camas mais antigas para a parte da rua do Espírito Santo" (Espanca, 1985, p. 38).

No corredor, existia uma porta que dava acesso a uma escada que conduzia ao pátio. Ou seja, o pátio estabelecia acesso ao primeiro andar através de duas escadas, que se encontravam situadas em locais opostos e que acedem, a primeira, ao lado Sudeste e, a segunda, ao do Noroeste.

Como mencionámos, no rés-dos-chãos, do lado Norte do pátio, havia ainda um aposento para inválidos, destinado a pessoas idosas, que estariam acamadas. Nessa ala localizava-se a capela onde se depositavam os defuntos do hospital, um compartimento para arrecadação de madeiras, o açougue e um compartimento para a palha, destinada ao enchimento dos enxergões ${ }^{26}$.

Cabia ao fiel averiguar a qualidade e quantidade dos produtos adquiridos e, no caso de não corresponderem à qualidade desejada, avisar a Comissão Administrativa ou a Mesa ${ }^{27}$. Em Abril de 1843, este funcionário deu conhecimento aos gestores da insatisfação da carne verde que chegava do açougue público, referindo a sua má qualidade e a "falta de peso", afirmando que a Santa Casa estava a ser mal servida e roubada no peso, pois pagava uma quantia que não recebia. Esta situação não era nova e tinha mesmo já motivado altercações por parte dos enfermos, levando a Comissão Administrativa a criar carneiros, tornando-se mais autónoma e procurando economizar mais ${ }^{28}$. A Santa Casa possuíra um rebanho no século XVIII, bem como uma capoeira (Araújo, 2000, p. 217), o que lhe possibilitava dosear o abate dos animais, de acordo com as necessidades sentidas, ao mesmo tempo que podia servir sempre produtos frescos e de boa qualidade aos enfermos (Esteves, 2012, pp. 289-308). Em 1831, a Misericórdia possuía 200 carneiros, tendo obtido licença da Câmara para os apascentar nos coutos e coutadas da vila, o que a 
levou a interferir junto do monarca para proibir o aforamento desses espaços.

Numa das sessões de 1843, a Misericórdia resolveu comprar um rebanho, decidindo que as peles dos carneiros fossem oferecidas à pessoa que os fosse buscar às pastagens, os matasse e os preparasse para serem confecionados. A posse de um rebanho implicava a existência de pastagens e a Santa Casa perante os anos de seca que se seguiram não reunia condições para o manter. Por isso, novamente se dirigiu ao monarca solicitando autorização para este poder pastar nos coutos da vila, autorização conseguida em 1850 para possuir até 200 carneiros nos referidos coutos, à semelhança do favor concedido aos religiosos do convento de São Francisco da vila ${ }^{29}$. Porém, no ano seguinte, a Comissão Administrativa ponderou os inconvenientes da carne adquirida para servir aos doentes, em virtude da falta de pastagens que se fazia sentir e chamou à reunião António João Gomes, o qual se comprometeu a fornecer o hospital de carne durante um ano, mediante o preço acordado ${ }^{30}$. Nessa altura, como se comprova, a Santa Casa já não tinha rebanho e comprava no açougue público a carne de que necessitava.

No lado Oeste do pátio do hospital funcionava uma arrecadação onde se armazenavam as roupas dos enfermos. Estes, quando chegavam, entregavam a sua roupa para vestirem uma camisa fornecida pela instituição. As suas peças eram lavadas e entregues à saída. Existiam ainda a "casinha do carvão" e o celeiro.

O administrador visitou cuidadosamente o hospital e descreveu-o com minúcia, possibilitando ao leitor acompanhar quase visualmente o complexo da Santa Casa. Na sequência, apontou algumas necessidades, sugerindo obras de conservação numa das enfermarias das mulheres, bem como em outros compartimentos. Mencionou ainda a necessidade de construção de mais uma enfermaria, quartos particulares, uma "casa destinada aos alienados até ao seu envio para Rilhafoles", casas de banho e uma sala para autópsias ${ }^{31}$. Ou seja, para além de verificar, o citado administrador analisou e aconselhou.

\section{OS DOENTES DO HOSPITAL}

Os pedidos de doentes mentais, designados no século XIX por alienados, cresceu na segunda metade do século XIX. Porém, a instituição que tutelava o hospital, por não reunir condições para os receber, não era favorável à sua entrada, embora a verdadeira razão fosse de natureza financeira. O que estava em causa era pressionar as famílias a mantê-los em suas casas e a arcar com a despesa inerente a esse custo. Existia ainda a possibilidade de os remeter para os hospitais psiquiátricos recentemente construídos, o de Rilhafoles (1848, em Lisboa) e depois o do Conde de Ferreira (1883, no Porto). Seguir esta opção era, todavia, cara e trabalhosa em termos processuais, pois impunha-se assumir os custos do envio e a despesa da sua permanência. Como escasseavam as receitas na confraria, a estratégia assentou em recebê-los durante algum tempo no hospital, até conseguir uma solução mais duradoira.

Devido ao tipo de doença, as famílias não os desejavam ter em sua companhia e algumas reconheciam a necessidade de um enquadramento mais favorável aos doentes, (Pereira; Gomes; Martins, 2005, p. 99). As soluções encontradas para tratar estes doentes eram escassas, sendo corrente o seu envio para as cadeias, embora o hospital de S. José operasse com uma enfermaria para doentes mentais desde o século XVI (Abreu, 2009, pp. 109-114). Com o avanço da ciência médica, no século XIX, estes doentes passaram a ser encaminhados para as novas unidades de tratamento (Pereira, 1986, pp. 87-88), embora no caso da vila alentejana os existentes ficavam a uma distância considerável (Esteves, 2012, pp. 298-301).

Porém, a implantação de hospitais para doentes mentais aliviou os restantes hospitais desses doentes, algo que se verifica em toda a Europa. A maior especialização e a separação dos doentes possibilitou tratamentos diferenciados, contribuindo para um avanço significativo em termos médicos (Pichot, 1984, p. 18).

Alguns doentes que estavam internados no hospital de Vila Viçosa perturbavam os restantes enfermos, facto que causava incómodo e obrigava a instituição a tomar medidas para remediar a situação. Era preciso protegê-los, mas também cuidar para que não molestassem os restantes internados (Tropé, 1994, pp. 239-242).

Conforme analisado num caso particular, a Misericórdia insistia junto da Câmara que esta passasse uma guia para o doente seguir para Rilhafoles (Rosen, 1974, pp. 214-227), mas o assunto, discutido em Mesa, causou de novo grande celeuma, por ser considerado uma hipoteca institucional, com uma des- 
pesa diária de 240 réis. Apesar das dificuldades, o doente seguiu para Lisboa e dois meses mais tarde faleceu ${ }^{32}$. O tratamento dos alienados era complexo, sobretudo para quem não vivia perto da capital ou do Porto e colocava muitos problemas às instituições que tinham responsabilidade no campo da saúde.

Também a sala para autópsias, apesar de corresponder a uma vontade dos irmãos, não foi concretizada, pelo menos até 1910. Aliás, até à República, o hospital só foi intervencionado em casos muito pontuais. A difícil conjuntura financeira da Santa Casa não o permitiu, pois todos os fundos disponíveis eram direcionados para o tratamento dos doentes e, mesmo assim, raramente chegavam, sendo necessário os irmãos adiantarem dinheiro do seu bolso para pagar dívidas correntes.

As sugestões do administrador do concelho eram várias, pertinentes e procuravam não apenas adaptar a instituição às necessidades sentidas, como tendiam a maior modernização. Este funcionário pensava que a instituição conseguia aumentar as suas receitas através do tratamento de doentes em quartos particulares, facto que ajudaria a tornar menor o desequilíbrio entre receitas e despesas. Nesse ano, as dívidas da Santa Casa ascendiam a 3.122.909 réis (sendo 1.167 .710 réis de dívidas ativas e 2.055.299 réis de dívidas passivas) ${ }^{33}$.

A análise das receitas e despesas ao longo do século XIX demonstra que o hospital era o maior sorvedouro de capitais da Santa Casa e nele centralizou-se praticamente toda a sua ação beneficente levada a cabo pela confraria. Como se tem vindo a demonstrar, várias Misericórdias concentravam as suas forças no campo da saúde (Lopes, 2002, pp. 90-91), respondendo à importância crescente deste setor na vida das populações.

Entre 1868 e 1869 o hospital internou 1256 pessoas e socorreu 869 em suas casas, enviando-lhes o médico e/ou cirurgião e fornecendo-lhes gratuitamente os medicamentos de que necessitavam. A Misericórdia dava preferência de internamento aos que sendo pobres se encontravam desamparados e ajudava em casa "as pessoas que preferem ser tratadas nos seus domicilios, e que não são indigentes ou totalmente desamparadas de família"34. Com os cortes impostos ao número de doentes admitidos ao hospital ao longo do século XIX, a confraria privilegiou os que sendo pobres se encontravam desamparados. Todavia, também aos que se mantinham em casa foram impostas restrições, sendo cada vez mais diminuto o número dos ajudados.

Mas quem eram os doentes admitidos no hospital para receberem tratamento? A análise efetuada aos internados possibilita constatar que estes eram maioritariamente homens de fora da vila. A maioria era constituída por trabalhadores provenientes do Norte e Centro do país. Destacavam-se os distritos da Guarda, Viseu, Coimbra, Vila Real, Porto, Viana do Castelo, Braga, Castelo Branco e Leiria como sendo os locais que mais gente enviavam para o Alentejo. Todavia, o Sul estava também representado, embora em menor quantidade. Havia doentes de Lisboa, Santarém, Beja e Faro ${ }^{35}$. O volume de doentes provenientes das terras do Sul mencionadas era muito mais reduzido.

Muitos dos que sendo de perto e foram internados no hospital estariam de passagem na vila, como acontecia com os vizinhos do Alandroal, Juromenha e Borba, onde também existiam hospitais. Outros residiriam ou estariam a trabalhar no concelho. Relativamente a estes últimos, predomina a gente da vila, mas encontrámos igualmente homens e mulheres das restantes paróquias concelhias: Bencatel, São Romão e Pardais.

Até meados do século XIX, o hospital era quase somente para gente de fora. A partir desta data, e por força da imposição dos critérios, passou apenas a receber alguns doentes, sendo posteriormente estabelecido o número de admitidos. Entre os internados encontramos vários estrangeiros, sobretudo provenientes do país vizinho. Com a fronteira tão próxima, não é de estranhar que fossem vários os espanhóis a residirem em Vila Viçosa. Vinham de Granada, Olivença, Badajoz, Galiza, Salamanca, Toledo e Sevilha. A maioria era natural de Olivença e Badajoz, localidades próximas de Vila Viçosa.

No que se refere às suas profissões, destacamos os criados pelo seu enorme peso, os jornaleiros, os "trabalhadores", os pastores (Rocha, 1991, pp. 646-647), as lavadeiras, os sacerdotes, os cozinheiros, os sapateiros, os alfaiates, os moços de recados, os alfaiates, os caleiros, os moleiros, os caldeireiros, os tosquiadores, etc. Muitos destes criados eram homens que cumpriam temporadas de trabalho no Alentejo. Como auferiam de um salário, eram obrigados a pagar o tratamento.

Por várias vezes, foi referido que os internados eram mendigos ${ }^{36}$. O perfil do doente que era denominado mendigo não é fácil de traçar, embora na sua maioria seja constituído por homens idosos e resi- 
dentes fora do concelho. Como é sabido, a palavra mendigo é polissémica, tal como a de pobre, e integra uma grande variedade de pessoas, que por diversas razões precisam de auxílio. Os mendigos que foram internados constituíam cerca de $10 \%$ dos doentes.

O estado de debilidade em que várias pessoas se encontravam levou a Santa Casa a aceitá-las no hospital, internando-as, mas mencionando que não estavam enfermas, apenas desamparadas, muito velhas e a precisar de apoio. Esta situação foi verificada somente durante a primeira metade do século XIX e não foi exclusiva deste centro hospitalar.

A partir da década de 30 do século XIX, os registos hospitalares foram alterados e, à boa maneira dos séculos XVI e XVIII dos assentos desta confraria, passaram a contemplar as peças de roupa que cada internado possuía, aquando do seu ingresso. Todos os homens usavam jaqueta, colete, polainas e chapéus, mas só alguns eram portadores de capotes. $\mathrm{O}$ uso de chapéu era vulgar, embora certos internados surgissem com gorros de lã. Era também frequente aparecerem com mantas, por ser usual o seu transporte às costas. Quase todos os que usavam mantas eram criados de servir.

Já as mulheres eram portadoras de um vestido ou saia, xaile ou mantilha, sapatos e lenço. Algumas levavam mais do que um lenço, ficando-nos a dúvida se seria para usar na cabeça, no pescoço ou se tratava de um lenço da mão. As mulheres usavam normalmente lenços, ao pescoço e na cabeça, por baixo do chapéu, para turvarem o sol e impedir que o suor escorresse pelo pescoço e pelas costas. O facto de também levarem várias saias, parece fazer crer que se faziam acompanhar de alguma ou de toda a roupa que possuíam ${ }^{37}$. As mulheres transportavam igualmente roupa interior. Para elas, eram mencionadas as "roupinhas", enquanto para os homens se referia as ceroulas. $O$ avental era outra das peças que acompanhava as mulheres, por isso também o envergavam no momento de entrada no hospital. As mulheres surgiam ainda com xailes e, em casos mais raros, com mantas, tal como muitos homens.

As peças de vestuário que alguns traziam eram tão velhas que não mereciam descrição, apenas se fazia uma pequena menção sobre o seu estado, para as considerar "muito velhas", ou como mais vulgarmente surge "fato muito velho". Muitos homens que cumpriam temporadas de trabalho nos campos de Vila Viçosa eram portadores de roupas esfarrapadas e consideradas em mau estado. Quando se registava que as peças estavam velhas significava que não tinham qualquer préstimo, nem mesmo serviam para farrapos. Todavia, nem sempre os portadores de roupa velha eram migrantes. Alguns que vestiam farrapos eram residentes em Vila Viçosa, ocupavam profissões ligadas aos ofícios e tinham família.

A movimentação dos pobres era grande, sobretudo quando enveredavam pela errância. Em Vila Viçosa surgiam muitos mendigos do outro lado da fronteira, vindos através de Badajoz e do Norte e Centro do país. Alguns seriam trabalhadores, que perdendo o trabalho, e perante a falta de recursos, se entregaram à mendicidade.

Para chegarem ao hospital, os pobres calçavam os sapatos ou as botas e colocavam o que melhor possuíam, mesmo assim as descrições apontam para bens muito degradados. Quase todos vestiam meias e dependendo da estação do ano e, do seu guarda-roupa, podiam ou não ser portadores de capotes.

O desenraizamento em que se encontravam os homens e as mulheres de fora, fazia-os transportar consigo as ferramentas que usavam no seu dia-a-dia ${ }^{38}$. Em caso de morte, a Santa Casa avisava a família para resgatar os bens do defunto, mas quando se tratava de migrantes ou de pobres errantes, era difícil estes serem procurados. Quando isto se verificava, ficavam, normalmente, para uso interno, sendo, por vezes, transformados, ou para serem oferecidos aos pobres ${ }^{39}$.

Para além do internamento, o hospital cuidava de muitos doentes que permaneciam em suas casas. Esta assistência foi muito significativa durante a primeira metade do século XIX, mas sofreu grandes cortes a partir de 1850 , com incidência particular na última década de Oitocentos e na primeira do período seguinte. Para se ser assistido ao domicílio era preciso efetuar uma petição e aguardar a decisão da Misericórdia. Os entraves lançados aos peticionários foram crescendo, obrigando-os a maiores justificações da sua necessidade e, em finais do século XIX, a condição de auxiliado tornou-se ainda mais restritiva.

Com o intuito de diminuir as despesas, em 1869 sob proposta do mesário Rainho, a Mesa passou a exigir que as petições que autorizavam os doentes tratados em casa a aviarem-se na farmácia dos medicamentos precisos fossem entregues na Misericórdia, não possibilitando aos seus portadores o seu uso sempre que necessitassem. Essa norma foi novamente reiterada em 1876, para a instituição poder atuar 
com mais segurança. A Mesa deliberou que se recorresse aos párocos em caso de necessidade de reforço de informação sobre os doentes que solicitavam ajuda para serem tratados no domicílio. Na tentativa de aliviar a situação financeira da instituição, o mesmo mesário elaborou uma lista em 1870 dos seus devedores, demonstrando o levado número de incumprimento. $O$ relatório provava ainda o caos financeiro em que a confraria se encontrava e responsabilizava anteriores Mesas de uma gestão danosa. Sem solução para resolver a difícil conjuntura, o órgão gestor resolveu cortar os salários dos seus funcionários, ascendendo em alguns casos a $50 \%$.

Apesar das dificuldades, o hospital era considerado pelo administrador do concelho com capacidade para tratar os doentes que o procuravam, reunindo condições de higiene e salubridade. Existiam também condições de segurança, muito embora alguns enfermos deixassem o internamento sem consentimento, provando que a fuga era possível e algumas pessoas estranhas ao serviço entrassem também sem estarem autorizadas. A colocação de cancelas e portas quer nas diferentes alas do pátio, quer mesmo na varanda do primeiro andar atesta a necessidade de limitar a passagem a pessoas exteriores, de forma a não prejudicar o sossego dos doentes e a manter o edifício e os doentes em segurança. Acrescia ainda o facto de se impor a obrigatoriedade de preservar todos os bens existentes. Nas décadas de 30 e 40 ocorreram vários assaltos na vila a diversas instituições e a Santa Casa foi também alvo dos larápios (Espanca, 1892, pp. 282-283). Nessa altura, o país vivia uma situação política muito instável e proporcionadora de grandes abusos (Bonifácio, 2010, pp. 34-35).

\section{CONCLUSÃO}

O hospital de Vila Viçosa espelha em 1870 a situação em que se encontrava a Misericórdia que o administrava, isto é, a crise em que vivia. Tratava-se de uma instituição de médias dimensões, considerada por alguns administradores do concelho um bom exemplo no contexto alentejano, embora estivesse pleno de privações.

O edifício é descrito pelo administrador do conceIho com grande minúcia, possibilitando ao leitor quase a sua visualização. O pátio, os corredores, as enfermarias, os diversos compartimentos, a cozinha e os quintais surgem quase como retratados, demons- trando que o funcionário régio o visitou com atenção, mas provavelmente já o conhecia anteriormente.

$\mathrm{Na}$ sua análise, denota a necessidade de obras, embora não as receba pelo menos até 1910 , pois a Misericórdia debatia-se no momento com uma enorme dívida ativa e passiva, procurando por todos os meios diminuir as despesas com os doentes. 0 complexo apresenta a mesma estrutura dos séculos anteriores, tendo, todavia, recebido acrescentos internos e reformulações, sem alterar a sua traça quinhentista. Procurou dotar-se de melhorias, respondendo às exigências dos tempos, nomeadamente com a construção de um quarto para parturientes, de quartos particulares, de espaços destinados à higiene dos internados e com o rasgar de janelas e outras aberturas de luz e ar, para que nos espaços se renovasse a ventilação. Foi-se adaptando às circunstâncias sempre com a preocupação de responder aos mais necessitados. As preocupações estendiam-se à alimentação, medicamentos e roupas dos internados, mas também à sua segurança e convalescença.

As despesas eram imensas para uma instituição que tinha visto as suas receitas diminuírem drasticamente com o corte do financiamento da Casa de Bragança. Com receitas minguadas e numa ocasião de grande inflação, o hospital foi obrigado a limitar o número de internados e a cortar também as ajudas aos tratados em domicílio. Se não existia dinheiro para curar os que o procuravam, muito menos havia para responder às exigências que se prendiam com o edifício. Todavia, apesar das dificuldades, como era o único hospital do concelho, a instituição era muito procurada, muito embora se esforçasse por manter o limite de internamentos estabelecido, procurando refrear as despesas.

A forma como lidou com os doentes mentais é sintomática do incómodo que estes lhe traziam, quer a si, quer aos demais hospitais do reino. Por um lado, não reunia condições para os receber, nem as normas que o regiam facilitavam essa receção, por outro as finanças da instituição desaconselhavam vivamente mais despesas sob grave responsabilidade de hipotecar o futuro. Se as indicações do administrador do conceIho iam no sentido de alguma modernidade, o que se ia sentindo timidamente em hospitais de dimensões semelhantes, como alguns estudos vêm demonstrando, aqui eram vistas com cautela, devido não somente à instabilidade sentida em termos de gestão, mas principalmente ao aumento de despesas. Por isso, tudo aconselhava prudência nas alterações terapêuticas, no melhoramento de edifício, entre outras. 


\section{NOTAS}

1. Foi da Casa de Bragança que saiu o duque D. João II em 1640 para no ano seguinte assumir a Coroa portuguesa, como rei D. João IV. A família dos Bragança reinou em Portugal entre 1641 e 1910.

2. Vila Viçosa era sede da Casa dos duques de Bragança.

3. As Misericórdias eram instituições formadas para o cumprimento das 14 obras de misericórdia. Surgiram em 1498 pela mão da Coroa, com a edificação da Santa Casa de Lisboa. Formandas por homens, integravam as elites locais.

4. A Misericórdia era governada por uma Mesa, composta por 13 elementos: sete nobres e seis oficiais.

5. Arquivo Distrital de Évora, (ADE), Fundo do Governo Civil, Orçamentos de receita e despesa de 1870-1871, cx. 984, peça no 33, fl. 1.

6. O hospital foi desativado em 2012, encontrando-se o edifício atualmente devoluto.

7. A instituição possuía botica própria desde 1773. Até então, as mezinhas administradas aos enfermos eram fornecidas pelos boticários da vila.

8. Funcionário que desempenhava várias funções.

9. $\mathrm{ADE}$, Fundo do Governo Civil, Orçamentos de receita e despesa de 1870-1871..., fl. 1.

10. Arquivo Municipal de Vila Viçosa (AMVV), Fundo da Misericórdia, Livro dos termos ou acordaos da Santa Caza 18231839, fl. 42

11. ADE, Fundo do Governo Civil, Orçamentos de receita e despesa de 1870-1871..., fl. 1v.

12. ADE, Fundo do Governo Civil, Orçamentos de receita $e$ despesa de 1870-1871..., fls. 1v-2.

13. ADE, Fundo do Governo Civil, Orçamentos de receita e despesa de 1870-1871..., fl. 1v.

14. A cama, o enxergão e a roupa tinham sido oferecidos pelo presidente da Comissão Administrativa, Tomé de Sousa Meneses, depois da morte da sua filha, sob condição de só ser usada por uma criança do sexo feminino.

15. Nessa altura, a Misericórdia regia-se pelo compromisso de 1618 da Misericórdia de Lisboa, por ordem de D. João IV, em 1806

16. AMVV, Fundo da Misericórdia, Livro de actas 1847-1857, fl. $47 \mathrm{v}$.

17. ADE, Fundo do Governo Civil, Orçamentos de receita e despesa de 1870-1871..., fl. 2.

18. ADE, Fundo do Governo Civil, Orçamentos de receita e despesa de 1870-1871..., fl. 2v.
19. ADE, Fundo do Governo Civil, Orçamentos de receita e despesa de 1870-1871..., fl. 2v.

20. Balandraus eram as capas pretas com capuz que os irmãos usavam em atos da instituição.

21. ADE, Fundo do Governo Civil, Orçamentos de receita e despesa de $1870-1871 \ldots$, fl. $2 \mathrm{v}$.

22. ADE, Fundo do Governo Civil, Orçamentos de receita e despesa de 1870-1871..., fl. 2v.

23. Era no consistório que os mesários se reuniam

24. ADE, Fundo do Governo Civil, Orçamentos de receita e despesa de 1870-1871..., fl. 3.

25. ADE, Fundo do Governo Civil, Orçamentos de receita e despesa de 1870-1871..., fls. 3-3v.

26. $\mathrm{ADE}$, Fundo do Governo Civil, Orçamentos de receita e despesa de 1870-1871..., fl. 3v.

27. ADE, Fundo do Governo Civil, Orçamentos de receita e despesa de 1870-1871..., fls. 3v.-4

28. Com o Liberalismo, o Estado impôs mudanças na gestão destas confrarias e sempre que necessário e substituiu as Mesas por Comissões Administrativas.

29. Arquivo da Casa de Bragança (doravante ACB), NNG, Ms. no 123, documento avulso, não paginado.

30. ACB, NNG, Ms. no 143, fls. 1-2; Ms. no 144, documento avulso, não paginado.

31. AMVV, Fundo da Misericórdia, Este livro he destinado para as Sessoens da Comissão Administrativa, fl. 30.

32. AMVV, Fundo da Misericórdia, Vária, documento avulso, não paginado.

33. Com exceção do provedor, todos os restantes 12 elementos da Mesa cumpriam, de forma rotativa, tarefas aos meses na instituição.

34. AMVV, Fundo da Misericórdia, Livro das Actas das Sessões da Comissão Administrativa da Misericordia de Villa Viçosa 1857-1860, fls. 21v.-24.

35. Casa senhorial, dotada de uma vasta propriedade.

36. AMVV, Copiador dos officios expedidos pela Secretaria da Misericordia de Vila Viçosa-Outubro de 1776 a Março de 1879, fl. 19.

37. AMVV, Fundo da Misericórdia, Servirá este Livro para as Actas das Sessoes da Administração, 1868-1877, fls. 23, 36v.

38. ADE, Fundo do Governo Civil, Orçamentos de receita e despesa de 1870-1871..., fl. 5v.

39. ADE, Fundo do Governo Civil, Orçamentos de receita $e$ despesa de 1870-1871..., fl. 6v. 


\section{BIBLIOGRAFIA}

Abreu, Laurinda (1999), Memórias da Alma e do Corpo. A Misericórdia de Setúbal na Modernidade, Viseu, Palimage Editores.

Abreu, Laurinda (2009), "A Misericórdia de Lisboa, o Hospital Real e os insanos: notas para uma introdução". En: Museu São João de Deus: Psiquiatria e História, Lisboa, Província Portuguesa da Ordem Hospitaleira de São João de Deus, pp. 109-114.

Abreu, Laurinda (2013), Pina Manique. Um Reformador no Portugal das Luzes, Lisboa, Gradiva.

Araújo, Maria Marta Lobo de (2000), Dar aos pobres e emprestar a Deus: as Misericórdias de Vila Viçosa e Ponte de Lima (séculos XVI-XVIII), Barcelos, Santa Casa da Misericórdia de Vila Viçosa; Santa Casa da Misericórdia de Ponte de Lima.

Araújo, Maria Marta Lobo de (2003), “O hospital do Espírito Santo de Portel na Época Moderna". Cadernos do Noroeste. Série História 3, 20 (1-2), pp. 341-409.

Araújo, Maria Marta Lobo de (2010), A Misericórdia de Vila Viçosa: de finais do Antigo Regime à República, Braga, Santa Casa da Misericórdia de Vila Viçosa.

Bonifácio, Maria de Fátima (2010), A Monarquia Constitucional 1807-1910, Lisboa, Texto Editora.

Catroga, Fernando (1993), "Morte romântica e religiosidade cívica". En: Mattoso, José (Dir.), História de Portugal, quinto volume, Lisboa, Círculo de Leitores, pp. 595-608.

Correia, Fernando da Silva (1943), "Os Hospitais Medievais Portugueses". A Medicina Contemporânea, ano LXI, no 12, pp. 180-190.

Cunha, Mafalda Soares da (2000), A Casa de Bragança 15601640. Práticas senhoriais e redes clientelares, Lisboa, Editorial Estampa.

Espanca, Joaquim José da Rocha (1892), Compendio de Noticias de Villa Viçosa, Redondo, Typographia F. Carvalho.

Espanca, José Joaquim da Rocha (1985), Memórias de Vila Viçosa, no 24, Vila Viçosa, Câmara Municipal se Vila Viçosa.

Esteves, Alexandra (2012), "La enfermedad como elemento de discriminación social en el Norte de Portugal, a finales del siglo XIX y princípios del XX". Estudios Humanísticos. Historia, no 11, 2012, pp. 298-308.

Esteves, Alexandra (2015), “A assistência à doença no Alto Minho oitocentista: o caso do hospital de Nossa Senhora da Visitação de Caminha". Asclepio. Revista de História de la Medicina y de la Ciência, no 67 (1), pp. 1-9.

Lopes, Maria Antónia (2002), “As Misericórdias de D. José ao final do século XX". En: Paiva, José Pedro (coordenador científico), Portugaliae Monumenta Misericordiarum, vol. I, Lisboa, Centro de Estudos de História Religiosa; União das Misericórdias Portuguesas, pp. 79-117.

Lopes, Maria Antónia (2008), "A Intervenção da Coroa nas Instituições de Protecção Social". Revista de História das Ideias, vol. 29, pp. 131-176.

Magalhães, Vera (2011), O Hospital Novo da Misericórdia de Viseu. Assistência, poder e imagem, Viseu, Santa Casa da Misericórdia de Viseu.

Oliveira, Luísa Tiago (1992), A saúde pública no vintismo, Lisboa, Ed. Sá da Costa.

Pacheco, António Fernando Bento (2008), De Todos-os-Santos a São José. Textos e contextos do esprital grande de Lixboa, Lisboa, Universidade Nova de Lisboa, Faculdade de Ciências Sociais e Humanas, dis. de mestrado policopiada.

Pereira, Ana Leonor (1986), “A institucionalização da loucura em Portugal". Revista Crítica de Ciências Sociais, no 21, pp. 87-88.

Pereira, Pedro Teixeira; Gomes, Eva; Martins, Olga (2005), “A alienação no Porto: o hospital de alienados do Conde de Ferreira (1883-1908)". Revista da Faculdade de Letras. História, Porto, III série, vol. 6, pp. 86-103.

Pereira, Ana Leonor; Pita, João Rui (2011), “A higiene: da higiene das habitações ao asseio pessoal". En: Mattoso, José (dir.), História da vida privada em Portugal. A Época Contemporânea, Lisboa, Círculo de Leitores, pp. 92-116.

Picão, José da Silva (1983), Através dos campos. Usos e costumes agrícolo-alentejanos, Lisboa, Publicações Dom Quixote.

Pichot P., Fernandes, Barahona (1984), Um século de Psiquiatria e a Psiquiatria em Portugal, Lisboa, Roche.

Rocha, Maria Manuela (1991), "Níveis de fortuna e estruturas patrimoniais no Alentejo: Monsaraz, 1800-1850". Análise Social, vol. XXVI, (112-113), pp. 629-651.

Sá, Isabel dos Guimarães (1996), “Os hospitais portugueses entre a assistência medieval e a intensificação dos cuidados médicos no período moderno". En: Congresso Comemorativo do V Centenário da Fundação do Hospital Real do Espírito Santo de Évora. Actas, Évora, Hospital do Espírito Santo, pp. 87-103.

Rosen, Gorge (1974), Locura y sociedad. Sociología histórica de la enfermedad mental, Madrid, Alianza Editorial.

Teixeira, Manuel C. (2007), "A evolução urbana de Vila Viçosa". Monumentos, no 27, pp. 19-24.

Tropé, Hélène (1994), Loucura y sociedad en la Valencia de los siglos XV al XVII, València, Diputación de València. 